OPEN ACCES

\title{
Biosynthesis of Silver Nanoparticles From Dictyota Bartayresiana Extract And Their Antifungal Activity
}

P. Senthil Kumar ${ }^{1}$, S. Sudha ${ }^{1} *$

${ }^{1}$ Molecular Diagnosis and Drug Discovery Laboratory, Department of Biotechnology, School of Life Sciences, Karpagam University, Coimbatore-640 021, Tamilnadu, India.

* Corresponding author. E-mail: sudhasellappa@gmail.com

\begin{abstract}
The synthesis, characterization and application of biologically synthesized nanomaterials are an important aspect in nanotechnology. The present study deals with the synthesis of silver nanoparticles (AgNPs) using aqueous extract of brown seaweed Dictyota Bartayresiana as the reducing agent. The formation of AgNPs was confirmed by UV-Vis Spectroscopy, Scanning electron microscopy (SEM) and Transmission electron microscopy (TEM). The synthesized AgNPs was predominately crystalline in shape, polydispersed and ranged from 15 to 40 nm in size. Fourier Transform Infra-Red (FTIR) spectroscopy analysis showed that the synthesized AgNPs was capped with bimolecular compounds which are responsible for reduction of silver ions. The antifungal effects of these AgNPs were studied against Humiclo insulans (MTCC 4520) and Fusarium dimerum (MTCC 6583). The present study indicates that AgNPs has considerable antifungal activity in comparison with other antifungal drugs.
\end{abstract}

Keywords: Dictyota Bartayresiana, Brown seaweed, Silver nanoparticles, Antifungal activity.

Citation: P. Senthil Kumar, S. Sudha. Biosynthesis of Silver Nanoparticles From Dictyota Bartayresiana Extract And Their Antifungal Activity. Nano Biomed. Eng. 2013, 5(2), 72-75. DOI: $10.5101 /$ nbe.v5i2.p72-75.

\section{Introduction}

Recently, nanotechnology research is raising advanced technology from the past few decades, because of their appliances in the areas of physics, chemistry, biology and medicine. Commonly, metal nanoparticles are synthesized and stabilized by means of chemical methods such as chemical reduction [1-4], electrochemical techniques [5], photochemical reactions in reverse micelles [6] and nowadays via green chemistry [7]. Synthesis of nanoparticles through biological methods is a good, environment friendly and economically alternative method.

Appliance of green chemistry to the synthesis of nanomaterials has an essential value in medicinal and scientific aspects [8,9]. Biologically synthesized silver nanoparticles (AgNPs) have wide range of applications because of their notable physical and chemical properties. There is a very limited data on the extra cellular biosynthesis of AgNPs using plants and their isloated pure compounds [10-12] and extracellular synthesis of AgNPs by using seaweed is very little [13].

In this study, we report on the biosynthesis of AgNPs by the reduction of aqueous $\mathrm{Ag}^{+}$with methanolic extract of Dictyota bartayresiana at direct sunlight condition. The amount of nanoparticles synthesized and qualitative differences between synthesized nanoparticles were also investigated by a range of analytical methods.

Dictyota bartayresiana J.V. Lamouroux (Class: Phaeophyceae, Order: Dictyotales, Family: Dictyotaceae) is an abundantly growing brown seaweed in coastals of south India. It is commonly occurs in inter tidal region of Gulf of Mannar Southeast coast of India. We have recently reported its antioxidant activity and antibacterial activity [14]. Keeping the biological perspectives in mind, the results reported here covers the biological synthesis of AgNPs and their antifungal activity.

\section{Materials and methods}

\subsection{Sample collection}

In the present study, Dictyota bartayresiana J.V. Lamouroux a brown seaweed was collected from Mandapam coastal region $\left(78^{\circ} 8^{\prime} \mathrm{E}, 9^{\circ} 17^{\prime} \mathrm{N}\right)$, Gulf of Mannar, Tamilnadu, South India. Samples were brought to laboratory in polythene bags and cleaned thoroughly with fresh water to remove adhering debris and associated biota. The algae were cleaned using brush for the removal of the epiphytes with distilled water. After cleaning, algae were dried in shade at room temperature for one week. 


\subsection{Extraction}

The whole plant of Dictyota bartayresiana were initially rinsed thrice in distilled water and dried on paper toweling, and samples ( $25 \mathrm{~g}$ ) were cut into fine pieces and boiled with $100 \mathrm{ml}$ of sterile distilled water for 5 minutes. The crude extract was passed through Whatman No.1 filter paper and the filtrates were stored at $4{ }^{\circ} \mathrm{C}$ for further use.

\subsection{Synthesis of AgNPs}

Silver nitrate $\left(\mathrm{AgNO}_{3}\right)$ as analytical grade (AR) was purchased from E. Marck (India). In the typical synthesis of silver nanoparticles, $10 \mathrm{ml}$ of the aqueous extract of Dictyota bartayresiana was added to $90 \mathrm{ml}$ of $1 \mathrm{mM}$ aqueous $\mathrm{AgNO}_{3}$ solution in $250 \mathrm{ml}$ conical flask and kept at room temperature for 48 hours at $120 \mathrm{rpm}$. Suitable controls were maintained throughout the conduct of experiments.

\subsection{UV-Vis spectral analysis}

The colour change in reaction mixture (metal ion solution + seaweed extract) was recorded through visual observation. The bio reduction of silver ions in aqueous solution was monitored by periodic sampling of aliquots $(0.5 \mathrm{ml})$ and subsequently measuring UV-vis spectra of the solution. UV-vis spectra of these aliquots were monitored as a function of time of reaction on UV-Vis spectrophotometer UV-2450 (Shimadzu).

\subsection{Scanning electron microscopic (SEM) analysis}

SEM analysis was done using Hitachi S-4500 SEM machine. Thin films of the sample were prepared on a carbon coated copper grid by just dropping a very small amount of the sample on the grid, extra solution was removed using a blotting paper and then the film on SEM grid were allowed to dry by putting it under a mercury lamp for $5 \mathrm{~min}$.

\subsection{Transmission electron microscopy (TEM) analysis}

The structural characterization of the AgNPs was carried out by TEM. The sample was prepared by airdrying drops of diluted solutions of the preparations on carbon films supported by copper grids.

\subsection{Fourier transform infra-red (FT-IR) spectroscopy analysis}

To remove any free biomass residue or compound that is not the capping ligand of the nanoparticles, the residual solution of $100 \mathrm{ml}$ after reaction was centrifuged at 5000 rpm for $10 \mathrm{~min}$. The supernatant was again centrifuged at $10000 \mathrm{rpm}$ for $60 \mathrm{~min}$ and the pellet was obtained. This is followed by redispersion of the pellet of AgNPs into 1 $\mathrm{ml}$ of deionized water. Thereafter, the purified suspension was freeze dried to obtain dried powder. Finally, the dried nanoparticles were analyzed by FTIR Nicolet Avatar 660 (Nicolet, USA).

\subsection{Antifungal activity}

The antifungal activity of AgNPs was evaluated against the following strains: Humiclo insulans (MTCC No. 4520) and Fusarium dimerum (MTCC No.6583). Cultures were maintained on potato dextrose agar (Hi Media, India) slants and they were subculture before use. The fungi studied were clinically important ones causing several infections and it is essential to overcome them through some active therapeutic agents.

Agar well diffusion assay method was followed, which involves swabbing the cultures in pre-sterilized nutrient agar plates potato dextrose agar plates and three wells were cut in the same using sterile cork borer. Each well was loaded with $50 \mu \mathrm{l}$ of solution in the following order: positive control, aqueous seaweed extract of Dictyota bartayresiana solution of AgNPs, and test sample methanolic extract. Then the sample loaded in potato dextrose agar plates were incubated at $37{ }^{\circ} \mathrm{C}$ for 48 hours. Then the formation of zone of inhibition was observed.

\section{Results and discussion}

The formation of AgNPs by reduction of aqueous $\mathrm{Ag}^{+}$during exposure to the aquous extract of Dictyota bartayresian showed reddish-brown colour, suggested the formation of AgNPs in solution which agreement with the statement reporting that AgNPs display reddish-brown in water [15]. These colours occur due to excitation of outer plasmon vibrations in the AgNPs [16]. This fundamental examination indicates the decline of $\mathrm{Ag}^{+}$and biosynthesis of the AgNPs. The Formation of metal nanoparticles by reduction of the aqueous metal ions during exposure of Dictyota bartayresian extract was followed by UV-Vis spectroscopy. UV-Vis absorption spectrum of AgNPs in the presence of extract is shown in Fig. 1. The Surface plasmon band in the AgNPs solution remains close to 419 $\mathrm{nm}$ throughout the reaction period, suggesting that the AgNPs were dispersed in the aqueous solution with no evidence for aggregation of them in UV-Vis absorption spectrum.

The SEM image (Fig. 2) showing the high density AgNPs synthesized by the D. bartayresiana further confirmed the development of silver nanostructures. The

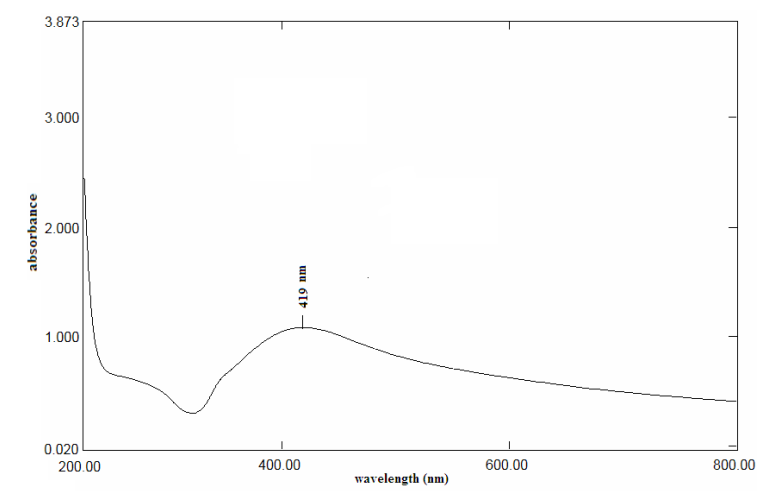

Fig. 1 UV-Vis absorption spectra of AgNPs synthesized by treating $1 \mathrm{mM} \mathrm{AgNO}_{3}$ solution with extract of Dictyota bartayresiana after 48 hours. 


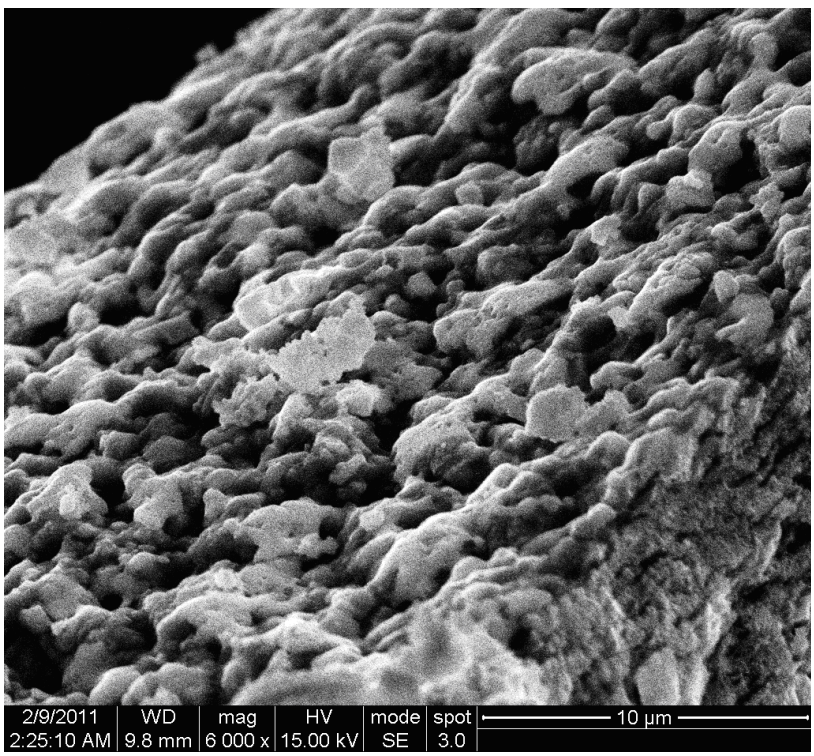

Fig. 2 SEM micrograph of AgNPs synthesized by treating $1 \mathrm{mM} \mathrm{AgNO}_{3}$ solution with extract of Dictyota bartayresiana after 48 hours.

SEM micrographs of nanoparticle obtained in the filtrate showed that AgNPs are well distributed without any aggregation in solution. The synthesized AgNPs was 21 $\mathrm{nm}$ and seems to be spherical in morphology as shown in TEM image (Fig. 3).

FT-IR analysis was used for the characterization of the extract and the resulting nanoparticles, absorption spectra of water soluble extract before and after reduction of $\mathrm{Ag}^{+}$. Absorbance bands seen at $3444.87 \mathrm{~cm}^{-1}$ and $2939.52 \mathrm{~cm}^{-1}$ were assigned to the stretching vibrations of primary and secondary amines respectively. These bands at 1955.82 $\mathrm{cm}^{-1}$ and $1643.35 \mathrm{~cm}^{-1}$ were known to be associated with the bending vibrations. In particular, $1535.34 \mathrm{~cm}^{-1}$ and $1400.32 \mathrm{~cm}^{-1}$ arises most probably from $\mathrm{C}=\mathrm{O}$ stretching $\beta$ dike tone and $\mathrm{CH}_{3}$ and $\mathrm{CH}_{2}$ bending vibrations (Fig. 4). The result revealed that the capping ligand of the AgNPs may be an aromatic compound or alkanes or amines.

Many studies have shown the antimicrobial effects of AgNPs [17-19]. However, only limited literatures supports the effects of AgNPs against fungal pathogens. Further the nanoparticles synthesis by green route by using Dictyota bartayresian extract was found highly toxic against clinically important fungal species at a concentration of $50 \mu \mathrm{l}$ AgNPs shown high antifungal activity against Muco circinelloids and a transitional activity was shown against Fusarium dimerum (Fig. 5). Similarly our previous study proved that the AgNPs synthesized from Gelidiella acerosa as an effective antifungal agent against pathogenic fungal strains [20]. The inhibitory activities in culture media of AgNPs reported were comparable with standard antifungal agent Clotrimazole. The present study showed a simple, rapid and economical route to synthesize AgNPs from brown seaweeds.

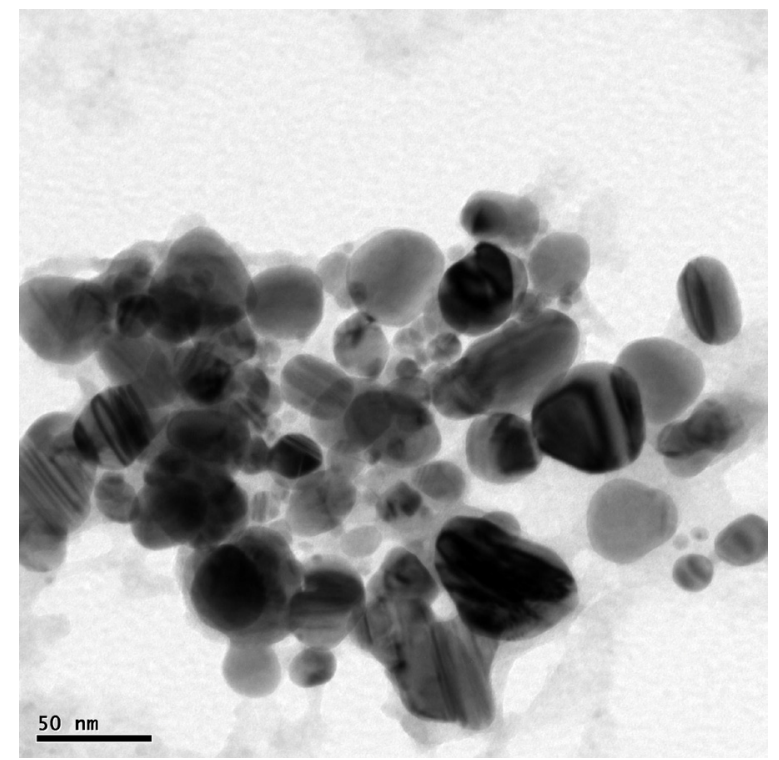

Fig. 3 TEM micrograph of AgNPs synthesized by treating $1 \mathrm{mM} \mathrm{AgNO}_{3}$ solution with extract of Dictyota bartayresiana after 48 hours.

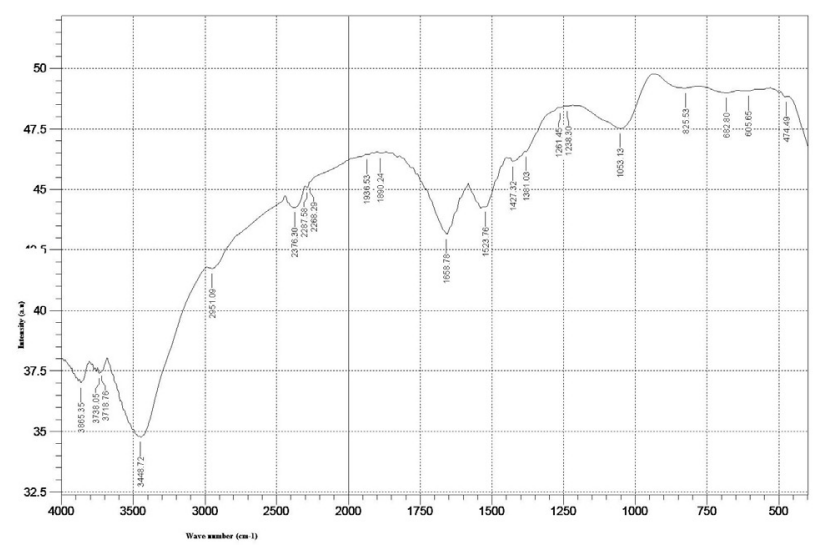

Fig. 4 FT-IR spectra of AgNPs synthesized by treating $1 \mathrm{mM} \mathrm{AgNO}_{3}$ solution with extract of Dictyota bartayresiana after 48 hours.

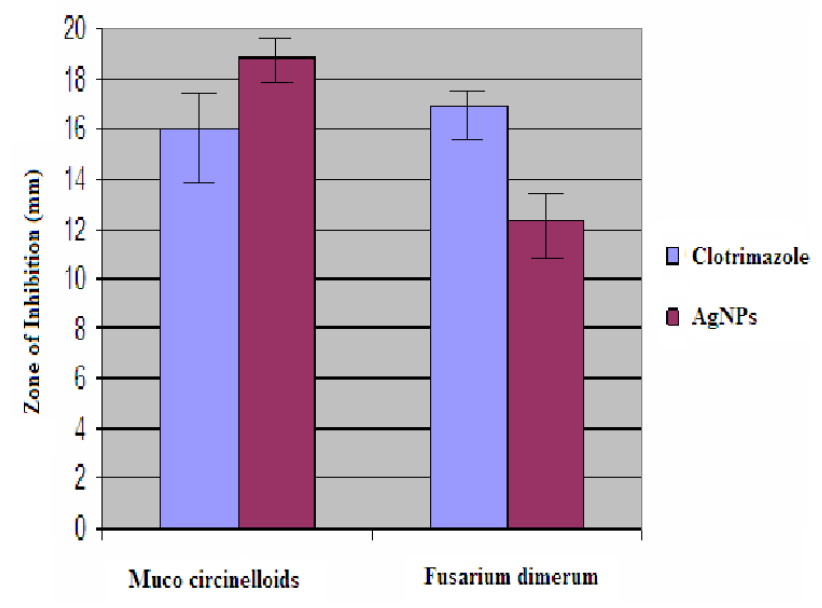

Fig. 5 Antifungal activity of AgNPs synthesized by reduction of $\mathrm{AgNO}_{3}$ with Dictyota bartayresiana extract against some selected fungal pathogens. Error bars refer to standard deviation by means of three replicates. 


\section{Conclusion}

Quick and green synthesis demonstrates that the environmentally benevolent Dictyota bartayresiana can be used as an effective capping as well as reducing agent for synthesis of AgNPs. The spectroscopic characterizations from UV-Vis spectroscopy, FT-IR, SEM and TEM support the formation and stability of the biosynthesized AgNPs. Further, the above AgNPs revealed to possess an effective antifungal property against Muco circinelloids and Fusarium dimerum. The present study emphasizes the use of seaweeds for the synthesis of AgNPs with potent antimicrobial effect. Synthesis of metallic nanoparticles using green resources like Dictyota bartayresiana is a substitute to chemical synthesis, since this novel green synthesis is a pollutant free and eco-friendly synthetic route for the biosynthesis.

\section{Acknowledgements}

The authors are grateful to the authorities of Karpagam University, Coimbatore, Tamilnadu, India for providing facilities and for their encouragement. Authors also thank Dr. M. Ganesan, Scientist, CSMCRIMarine Algal Research station, Mandapam camp, Tamilnadu, India for the species identification.The authors would like to acknowledge Department of Nono Science and Technology, Bharathiar University for the SEM analysis.

\section{References}

1 Balantrapu K., Goia D., Silver nanoparticles for printable electronics and biological applications. J.Mater. Res. 2009; 24:2828-2836.

2 Tripathi RM., Saxena A., Gupta N., Kapoor H., Singh R., High antibacterial activity of silver nanoballs against E.coli MTCC 1302, S.typhimurium MTCC 1254, B.subtilis MTCC 1133 and P. aeruginosa MTCC 2295. Dig. J. Nanomater Bios. 2010; 5: 323-330.

3 Kumar P., Senthamil Selvi S., Lakshmi Prabha A., Prem Kumar K., Ganeshkumar RS., GovindarajuM., Synthesis of silver nanoparticles from Sargassum tenerrimum and screening phytochemicals for its anti-bacterial activity. Nano Biomed. Eng. 2012, 4: 12-16.

4 Logaranjan K., Devi S., Pandian K., Biogenic Synthesis of Silver Nanoparticles Using Fruit Extract of Ficus Carica and Study Its Antimicrobial Activity. Nano Biomed. Eng. 2012, 4, 177-182.

5 Rodríguez-Sánchez L., Blanco M.C., López-Quintela MA., Electrochemical synthesis of silver nanoparticles. J. Phys. Chem.B. 2000; 104: 9683-9688.

6 Taleb A., Petit C., Pileni M., Optical properties of self-assembled 2D and 3D superlattices of silver nanoparticles. J. Phys. Chem. B. $1998 ; 102: 2214-2220$.
7 Begum NA., Mondal S., Basu S., Laskar RA., Mandal D., Biogenic synthesis of Au and Ag nanoparticles using aqueous solutions of black tea leaf extracts. Colloids Surf. B Biointerf. 2009; 71:113-118.

8 Zhang G., Keita B., Dolbecq A., Mialane P., Se'cheresse F., Miserques F, Nadjo L., Green Chemistry-Type One-Step Synthesis of Silver Nanostructures Based on $\mathrm{Mo}^{\mathrm{V}}-\mathrm{Mo}^{\mathrm{VI}}$ Mixed-Valence Polyoxometalates. Chem. Mater. 2007; 19: 5821-5823.

9 Kattumuri V., Katti K., Bhaskaran S., Boote E.J., Casteel S.W., Fent G.M., Gum arabic as a phyto-chemical construct for the stabilization of gold nanoparticles: in vivo pharmacokinetics and X-ray contrast-imaging studies. Small. 2007; 3: 333-341.

10Song JY., Kim B.S., Biological synthesis of bimetallic Au/Ag nanoparticles using Persimmon (Diopyros kaki) leaf extract. Korean.J. Chem. Eng. 2008; 25: 808-811.

11 Chandran S.P., Chaudhary M., Pasricha R., Ahmad A., Sastry M., Synthesis of Gold Nanotriangles and Silver Nanoparticles Using Aloe vera Plant Extract. Biotechnol Prog. 2000; 22:577-583.

12 Kasthuri J., Kathiravan K., Rajendiran N., Phyllanthin-assisted biosynthesis of silver and gold nanoparticles: a novel biological approach. J. Nanopart. Res 2009; 11:1075-1085.

13 Govindaraju K., Kiruthiga V., Ganesh Kumar V., Singaravelu G., Extracellular synthesis of silver nanoparticles by a marine alga, Sargassum wightii Grevilli and their antibacterial effects. J. Nanosci. Nanotechnol. 2009; 9: 5497-5501.

14Senthilkumar P., Sudha S., Stella C., Antioxidant properties of methanolic extract of Dictyota batresiana from south east coast of India. J. Pharm. Res. 2010; 3: 512974.

15 Boulch, F., Schouler M. C., Donnadieu P., Chaix J. M., Djurado E., Sastry M., Patil V., Sainkar SR., Domain size distribution of Y- Electrostatically controlled diffusion of carboxylic acid derivatized silver colloidal particles in thermally evaporated fatty amine films. J. Phys. Chem. B. 1998; 102:1404-1410.

16Mulvaney P., Surface plasmon spectroscopy of nanosized metal particles. Langmuir. 1996; 12: 788-800.

17 Kim KJ., Sung W.S., Moon SK, Choi J.S., Kim J.G., Lee D.G., Antifungal effect of silver nanoparticles on dermatophytes. J. Microbiol. Biotechn.2008; 18: 1482-1484.

18 Kim K. J., Sung W. S., Suh B. K., Antifungal activity and mode of action of silver nano-particles on Candida albicans. BioMetals. 2009; 22: 235-242.

19 Klasen H.J., A historical review of the use of silver in the treatment of burns. II. Renewed interest for silver. Burns. 2000; 26:131-138.

20 Vivek M., Senthilkumar P., Steffi S., Sudha S., Biogenic Silver Nanoparticles by Gelidiella acerosa Extract and their Antifungal Effects. Avicenna J. Med. Biotechnol. 2011; 3:143-148.

Copyright: (c) 2013 P. Senthil Kumar, S. Sudha. This is an open-access article distributed under the terms of the Creative Commons Attribution License, which permits unrestricted use, distribution, and reproduction in any medium, provided the original author and source are credited. 